\title{
Genome Sequences of Three Races of Peronospora effusa: A Resource for Studying the Evolution of the Spinach Downy Mildew Pathogen
}

\author{
Chunda Feng, ${ }^{1}$ Kurt H. Lamour, ${ }^{2}$ Burt H. Bluhm, ${ }^{1}$ Sandeep Sharma, ${ }^{1}$ Sandesh Shrestha, ${ }^{2}$ \\ Braham Deep Singh Dhillon, ${ }^{1}$ and James C. Correll ${ }^{1, \dagger}$ \\ ${ }^{1}$ Department of Plant Pathology, University of Arkansas, Fayetteville 72701 \\ ${ }^{2}$ Department of Entomology and Plant Pathology, University of Tennessee, Knoxville 37996
}

\begin{abstract}
Downy mildew disease, caused by the obligate oomycete pathogen Peronospora effusa, is the most important economic constraint for spinach production. Three races (races 12, 13, and 14) of $P$. effusa have been sequenced and assembled. The draft genomes of these three races have been deposited to GenBank and provide useful resources for dissecting the interaction between the host and the pathogen and may provide a framework for determining the mechanism by which new races of the pathogen are rapidly emerging.
\end{abstract}

\section{Genome Announcement}

Spinach is a popular and nutritious vegetable (Morelock and Correll 2008). Current highdensity plant populations for fresh-market spinach production provide conditions highly conducive for disease development. Downy mildew disease, caused by the obligate pathogen Peronospora effusa ( $=P$. farinosa f. sp. spinaciae), is the most economically important disease of spinach (Correll et al. 2011). The use of resistant cultivars to manage downy mildew applies strong selection pressure on the pathogen, and 14 of the 17 races of $P$. effusa have been identified in recent years (Feng et al. 2014, 2018; Irish et al. 2003, 2007). The rapid appearance of new races of this pathogen make it a challenge to use resistance as a sustainable management tool, threatening spinach production. However, the mechanism of virulence evolution in $P$. effusa is largely unknown. Sequencing the genome of this pathogen will ultimately improve the fundamental understanding of the genes involved in virulence and the mechanisms underlying host-pathogen interactions and pathogen evolution.

$P$. effusa is an obligate pathogen and cannot be grown in axenic culture. Thus, sporangia of three strains of $P$. effusa (UA2209, UA0510C, and UA4410, representing races 12, 13, and 14, respectively) (Feng et al. 2014) were recovered from infected spinach leaves by washing sporangia off with deionized water and concentrated by centrifugation before DNA extraction. Total genomic DNA of each strain was isolated using the cetyltrimethylammonium bromide method. After enzymatic fragmentation, 200-bp libraries were constructed and then ran in one lane of 100-bp paired-end HiSeq2000. Strain UA0510C was sequenced at the Genomics Core Facility, Purdue University (West Lafayette, IN, U.S.A.), and UA2209 and UA4410 were sequenced at BGI (Shenzhen, China). Approximately 128 to 148 million 100-bp paired-end reads (31 to 35 gigabases) were obtained for each strain (Table 1). In order to remove any nontarget sequences from other sources such as epiphytic bacteria, the raw reads were mapped to a set of $483-\mathrm{Mb}$ oomycete reference genome sequences (downloaded from GenBank on 8 October 2015) with

\footnotetext{
${ }^{\dagger}$ Corresponding author: James C. Correll; E-mail: jcorrell@uark.edu
}

Accepted for publication 15 June 2018.

\section{Funding}

This research was supported by James Correll (United States Department of Agriculture-National Institute of Food and Agriculture Specialty Crop Research Initiative project grant number 2012-5118120167). 
Table 1. Assembly statistics of the three races of Peronospora effusa

\begin{tabular}{lccc} 
Assembly & Race 12 (UA2209) & Race 13 (UA0510C) & Race 14 (UA4410) \\
Raw read (Mb) & 33,456 & 31,668 & 34,682 \\
$\begin{array}{l}\text { Percentage of reads that match } \\
\quad \text { oomycete }\end{array}$ & 84.35 & 61.68 & 81.43 \\
Number of contigs & 4,060 & & \\
Largest contig (bp) & 141,591 & 4,384 & 4,020 \\
Total length (bp) & $25,220,668$ & 168,434 & 131,290 \\
GC (\%) & 46.9 & $23,993,179$ & $24,880,370$ \\
N50 & 21,343 & 46.88 & 46.91 \\
L50 & 340 & 18,134 & 22,141 \\
\hline
\end{tabular}

Burrows-Wheeler Aligner (BWA) software using a short-read algorithm (Li and Durbin 2009); then, the mapped raw reads, approximately 62 to $84 \%$ of the original total, were assembled using CLC Genomics Workbench 7 with de Bruijn graph assembly. The draft genome of each strain was approximately $25 \mathrm{Mb}$, which represented approximately $50 \%$ of the estimated genome size but approximately $78 \%$ of the estimated genome size of a race 1 strain previously reported (Klein et al. 2017). When the completeness of the genome sequences was assessed by comparing the draft genome sequences to the 290 eukaryotic single-copy orthologs using the software BUSCO (Waterhouse et al. 2018), the results indicated that 82,81 , and $83 \%$ of the genomes were complete or partially complete $(71,68$, and $72 \%$ were complete and 11,13 , and $11 \%$ were partially finished) for races 12,13 , and 14 of $P$. effusa, respectively. The incompleteness may be due to loss of $P$. effuse-specific reads when only reads mapped to the oomycete reference genome were used for assembly. The draft genomes comprised approximately 4,000 to 4,400 contigs with the GC content of $46.9 \%$. More than $50 \%$ of the sequences were contributed by 327 to 376 contigs (L50) that were $18 \mathrm{~kb}$ or longer (N50), with the largest contigs being 141, 168, and $131 \mathrm{~kb}$ for strains UA2209, UA0510C, and UA4410, respectively (Table 1).More than 15,000 single-nucleotide polymorphisms (SNP) were identified from the three sequenced genomes using BWA and SAMtools (Li et al. 2009). Forty-six selected SNP have been used to investigate the population diversity of $P$. effusa and comparative genomic analysis revealed that both sexual and asexual reproduction may have generated novel genotypes with unique virulence phenotypes. (Lyon et al. 2016).

This whole-genome shotgun project has been deposited in DDBJ/ENA/GenBank under the accession numbers NPIT00000000, NPIU00000000, and NPIV00000000. The versions described in this article are the first versions (NPIT01000000, NPIU01000000, and NPIV01000000).

\section{Acknowledgments}

We thank J. Pummill, D. Chaffin, and P. Wolinski at the Arkansas High Performance Computing Center, University of Arkansas, Fayetteville for their help.

\section{Literature Cited}

Correll, J. C., Bluhm, B. H., Feng, C., Lamour, K., du Toit, L. J., and Koike, S. T. 2011. Spinach: Better management of downy mildew and white rust through genomics. Eur. J. Plant Pathol. 129:193-205.

Feng, C., Correll, J. C., Kammeijer, K. E., and Koike, S. T. 2014. Identification of new races and deviating strains of the spinach downy mildew pathogen Peronospora farinosa f. sp. spinaciae. Plant Dis. 98:145-152.

Feng, C., Saito, K., Liu, B., Manley, A., Kanuneijer, K., Mauzey, S. J., Koike, S., and Correll, J. C. 2018. New races and novel strains of the spinach downy mildew pathogen Peronospora effusa. Plant Dis. 102:613-618.

Irish, B. M., Correll, J. C., Koike, S. T., and Morelock, T. E. 2007. Three new races of the spinach downy mildew pathogen identified by a modified set of spinach differentials. Plant Dis. 91:1392-1396.

Irish, B. M., Correll, J. C., Koike, S. T., Schafer, J., and Morelock, T. E. 2003. Identification and cultivar reaction to three new races of the spinach downy mildew pathogen from the United States and Europe. Plant Dis. 87:567-572.

Klein, J., van Verk, M., and van den Ackerveken, G. 2017. Identification and monitoring of effector proteins in the spinach downy mildew pathogen
Peronospora farinosa. Page 227 in: 29th Fungal Genet. Conf., Pacific Grove, CA.

$\mathrm{Li}, \mathrm{H}$., and Durbin, R. 2009. Fast and accurate short read alignment with BurrowsWheeler transform. Bioinformatics 25:1754-1760.

Li, H., Handsaker, B., Wysoker, A., Fennell, T., Ruan, J., Homer, N., Marth, G., Abecasis, G., Durbin, R., and 1000 Genome Project Data Processing Subgroup. 2009. The Sequence Alignment/Map format and SAMtools. Bioinformatics 25:2078-2079.

Lyon, R., Correll, J., Feng, C., Bluhm, B., Shrestha, S., Shi, A., and Lamour, K. 2016. Population structure of Peronospora effusa in the Southwestern United States. PLoS One 11:e0148385.

Morelock, T. E., and Correll, J. C. 2008. Spinach breeding. Pages 189-218 in: Vegetable. I. J. Prohens and F. Neuz, eds. Springer, New York.

Waterhouse, R. M., Seppey, M., Simão, F. A., Manni, M., Ioannidis, P., Klioutchnikov, G., Kriventseva, E. V., and Zdobnov, E. M. 2018. BUSCO applications from quality assessments to gene prediction and phylogenomics. Mol. Biol. Evol. 35:543-548.

\section{Author-Recommended Internet Resource}

Genomics Workbench 7: https://www.qiagenbioinformatics.com/ 